\title{
TRASTORNO LÍMITE DE LA PERSONALIDAD: A PROPÓSITO DE UN CASO
}

\section{ALBA FERNÁNDEZ FALCES ${ }^{1}$, PATRICIA CARRERA MARTÍN², MARÍA RAMAJO HOLGADO³ Y MARTA DÍAZ NOAÍN ${ }^{4}$}

${ }^{1}$ Enfermera especialista en salud mental. Servicio de Urgencias Extrahospitalarias (Osasunbidea).

²Enfermera de atención primaria. CS Isaba (Osasunbidea).

${ }^{3}$ Médico especialista en medicina familiar y comunitaria. CS Isaba (Osasunbidea).

${ }^{4}$ Médico especialista en medicina familiar y comunitaria. Servicio de Urgencias Extrahospitalarias

(Osasunbidea).

\section{INTRODUCCIÓN}

Según la quinta edición del Manual diagnóstico y estadístico de los trastornos mentales (DSM-5)리 trastorno límite de la personalidad (TLP) se define como un patrón general de inestabilidad en las relaciones interpersonales, de la autoimagen y de los afectos, de impulsividad intensa, que comienza en las primeras etapas de la edad adulta.

Los estudios realizados en poblaciones clínicas han mostrado que es el trastorno de la personalidad más frecuente, ya que entre el 30 y el $60 \%$ de los pacientes con trastorno de la personalidad tienen TLP. En términos generales, se estima que su prevalencia oscila entre el 1 y el $2 \%$ de la población general, entre el 11 y el $20 \%$ en pacientes ambulatorios, entre el 18 y el $32 \%$ en pacientes hospitalizados en unidades psiquiátricas y entre el 25 y el $50 \%$ en la población reclusa².

Correspondencia: Alba Fernández Falces

Correo electrónico: albafernandezfalces@gmail.com
Respecto a la distribución por sexos, es más frecuente en mujeres que en hombres, con una relación estimada de 3:1. Cuando se realiza el diagnóstico, la mayoría de los pacientes tienen una edad comprendida entre los 19 y los 34 años y pertenecen a grupos de nivel socioeconómico medio².

A continuación, se describe el caso clínico de una paciente con diagnóstico de TLP y los cuidados de enfermería proporcionados.

\section{DESCRIPCIÓN DEL CASO}

Mujer de 32 años que ingresa en la unidad de agudos derivada por su psiquiatra de referencia por un cuadro depresivo atípico con escasa respuesta y riesgo autoagresivo. Lleva realizando seguimiento psiquiátrico ambulatorio desde hace cinco años.

No tiene antecedentes personales de interés.

Actualmente, está en tratamiento con: duloxetina de 60 mg, olanzapina de 20 mg y lorazepam de 1 mg.

Se presenta consciente, orientada y colaboradora. Presenta una marcada labilidad emocional y, en ocasiones, se muestra ligeramente irritable. 
Se define como una persona muy autoexigente con ella misma tanto en el tema del trabajo y estudios como en su actual relación de pareja; está casada. Ha mantenido un funcionamiento adecuado en estos últimos años, hasta que hace dos meses despiden del trabajo a su marido y, asimismo, ella comienza con problemas laborales.

Presenta insomnio de varios días de evolución.

\section{VALORACIÓN GENERAL}

Se ha llevado a cabo la valoración del caso a partir de los patrones funcionales de Marjory Gordon (tabla 1).

\section{DIAGNÓSTICO, PLANIFICACIÓN Y EJECUCIÓN DE LOS CUIDADOS}

Se utilizó la taxonomía NANDA (North American Nursing Diagnosis Association), NOC (Nursing Outcomes Classification), NIC (Nursing Interventions Classification) (NNN) para determinar las etiquetas diagnósticas y la formulación de los diagnósticos enfermeros y establecer los resultados e intervenciones de enfermería (tabla 2) $)^{3-5}$.

\section{EVALUACIÓN DEL PLAN DE CUIDADOS Y SEGUIMIENTO}

Tras la primera semana de ingreso en la unidad de agudos, la paciente incrementó sus conductas auto- lesivas, dificultando en varias ocasiones el tratamiento debido a la imposibilidad de trabajar con ella por sus numerosas negativas.

Se le comenzó a instruir en estrategias para el control de los impulsos autolesivos (uno de los recursos que más a ayudó a esta paciente fue el realizar duchas con agua fría cuando sentía la necesidad de autolesionarse), con lo que se consiguió que disminuyeran.

Tras dos meses de ingreso y dado el gran apoyo familiar de la paciente, se le derivó a un hospital de día para continuar mejorando sus conocimientos sobre la enfermedad y continuar trabajando de manera muy estrecha con la psicóloga de dicho centro el diagnóstico enfermero de baja autoestima crónica.

\section{CONCLUSIÓN}

Debido a la importante incidencia de este tipo de trastorno en nuestra sociedad actual y a la complejidad y especificidad de algunos trastornos límite, se plantea la necesidad de asistencia muy concreta y específica.

El manejo de estos pacientes es un reto para las enfermeras de salud mental, puesto que cuentan con los conocimientos y actitudes necesarias para aplicar intervenciones eficaces para ayudar a estas personas a alcanzar un bienestar social y personal en colaboración con el resto del equipo multidisciplinario.

Ayudarles a construir estrategias eficaces de conducta y habilidades en la resolución de problemas son elementos clave para mejorar su calidad de vida. 


\begin{tabular}{|c|c|}
\hline Patrones & Valoración \\
\hline $\begin{array}{l}\text { Percepción-manejo } \\
\text { de la salud }\end{array}$ & $\begin{array}{l}\text { - Refiere encontrarse «mal»; no aguanta «vivir así». Manifiesta encontrarse en un } \\
\text { estado de estrés permanente, que, en principio, relaciona con problemas } \\
\text { laborales propios y el despido de su marido. No sale de casa desde hace un mes. } \\
\text { - No presenta alteración respecto a sus hábitos higiénicos. } \\
\text { - No tiene hábitos tóxicos. } \\
\text { - Adecuada adherencia al tratamiento. }\end{array}$ \\
\hline $\begin{array}{l}\text { Nutricional- } \\
\text { metabólico }\end{array}$ & $\begin{array}{l}\text { - Datos antropométricos normales. } \\
\text { - No presenta alteraciones en este patrón. }\end{array}$ \\
\hline Eliminación & - No presenta alteraciones en este patrón. \\
\hline Actividad-ejercicio & $\begin{array}{l}\text { - Apatía. } \\
\text { - Fatiga. } \\
\text { - Cansancio. } \\
\text { - Únicamente emplea el tiempo libre en permanecer en casa; hace un mes que no } \\
\text { sale de esta, excepto para trabajar, ya que refiere: «tengo miedo de todo, los } \\
\text { ruidos me molestan, la gente...». }\end{array}$ \\
\hline Sueño-descanso & $\begin{array}{l}\text { - Sensación de no haber descansado cuando se despierta. } \\
\text { - Le cuesta conciliar el sueño; está recurriendo a medicación para dormir. }\end{array}$ \\
\hline Cognitivo-perceptivo & $\begin{array}{l}\text { - Consciente y orientada. } \\
\text { - Capacidades cognitivas conservadas; se considera muy capaz en su trabajo. } \\
\text { - Refiere este último mes encontrarse intranquila e irritable con su entorno. }\end{array}$ \\
\hline $\begin{array}{l}\text { Autopercepción- } \\
\text { autoconcepto }\end{array}$ & $\begin{array}{l}\text { - Baja autoestima; últimamente se ha visto disminuida debido a las continuas } \\
\text { descalificaciones en la empresa. } \\
\text { - En ocasiones, se muestra totalmente pasiva con todo lo que le rodea, } \\
\text { intercalándolo, en otras ocasiones, con autoagresividad (se golpea dándose } \\
\text { puñetazos, pegándose contra la pared, etc.), y gran angustia. } \\
\text { - Verbaliza frecuentemente expresiones autonegativas, de desesperanza, inutilidad, } \\
\text { etc. }\end{array}$ \\
\hline Rol-relaciones & $\begin{array}{l}\text { - Casada desde hace un año. Pareja y familia muy involucrados en su enfermedad } \\
\text { (han leído mucho acerca de los síntomas de la paciente, llegando a } \\
\text { diagnosticarla). } \\
\text { - Gran insatisfacción en el resto de relaciones sociales fuera del entorno familiar, } \\
\text { haciendo hincapié en las relaciones laborales. } \\
\text { - Dentro de la unidad, muy integrada, comunicativa y muy pendiente del resto de } \\
\text { pacientes. }\end{array}$ \\
\hline $\begin{array}{l}\text { Sexualidad- } \\
\text { reproducción }\end{array}$ & $\begin{array}{l}\text { - Manifiesta querer quedarse embarazada, aunque ella misma afirma que este no } \\
\text { es el momento más adecuado para hacerlo. }\end{array}$ \\
\hline $\begin{array}{l}\text { Adaptación y } \\
\text { tolerancia al estrés }\end{array}$ & $\begin{array}{l}\text { - Ante las situaciones estresantes, su forma de afrontamiento es mediante la } \\
\text { autoagresividad («Es lo único que me disminuye esta angustia que yo tengo...»). } \\
\text { Conforme avanza el ingreso, las crisis de autoagresividad han aumentado } \\
\text { considerablemente. } \\
\text { - La mayor parte del día manifiesta encontrarse muy angustiada. } \\
\text { - Nos relata sueños: «He soñado que estaba dormida y los cuervos me sacaban los } \\
\text { ojos...», «Me cortaban trocito a trocito todo mi cuerpo...». }\end{array}$ \\
\hline Valores y cr & - No menciona pertenecer a ninguna religión ni tener creencias específicas. \\
\hline
\end{tabular}




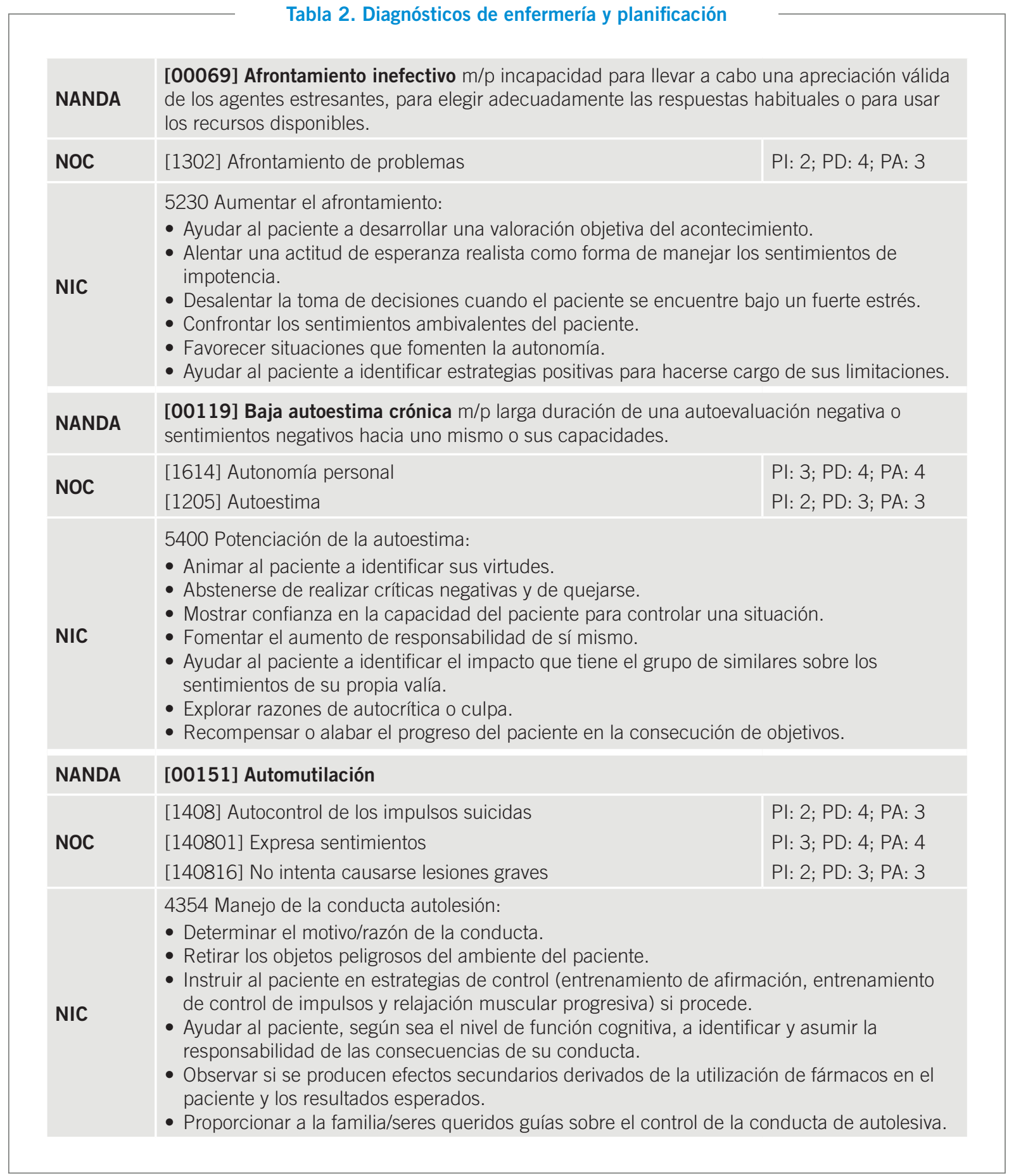

m/p: manifestado por; NANDA: diagnóstico de enfermería; NIC: intervención de enfermería; NOC: criterio de resultado; PA: puntuación alcanzada ; PD: puntuación diana; PI: puntuación inicial. 


\section{BIBLIOGRAFÍA}

1. Asociación Americana de Psiquiatría. Guía de consulta de los criterios diagnósticos del DSM-5 ${ }^{\mathrm{TM}}$. Arlington: Asociación Americana de Psiquiatría; 2014.

2. Grupo de trabajo de la Guía de práctica clínica sobre trastorno límite de la personalidad; Fórum de Salud Mental y AIAQS (coords). Guía de práctica clínica sobre trastorno límite de la personalidad [Versión resumida]. Barcelona: Agència d'Informació, Avaluació i Qualitat en Salut. Servei Català de la Salut. Pla Director de Salut Mental i Addiccions. Departament de Salut. Generalitat de Catalunya; 2011.
3. NANDA International. Herdman TH, Kamitsuru S (eds.). Diagnósticos enfermeros. Definiciones y clasificación 2015- 2017. 10. ${ }^{a}$ ed. Barcelona: Elsevier España, S.L; 2015.

4. Moorhead S, Johnson M, Maas ML, Swanson E (eds.). Clasificación del resultado de enfermería (NOC). Medición de resultados en salud. 5. ${ }^{a}$ ed. Barcelona: Elsevier España, S.L; 2014.

5. Bulechkek GM, Butcher HK, Dochterman JM, Wagner CM (eds.). Clasificación de intervenciones de enfermería (NIC). 6. ${ }^{a}$ ed. Barcelona; Elsevier España, S.L: 2014. 